\section{Influence of Wing Section and Wing Setting Angle on the Starting Performance of a Darrieus Wind Turbine with Straight Wings*}

\author{
Futoshi TANAKA**, Kiyoshi KAWAGUCHI***, Shinichi SUGIMOTO*** \\ and Masahiro TOMIOKA*** \\ **Department of Mechanical Engineering, University of Fukui, \\ 3-9-1 Bunkyo, Fukui-shi, Fukui 910-8507, JAPAN \\ E-mail: f-tanaka@u-fukui.ac.jp \\ ***Department of Mechanical and Intellectual Systems Engineering, University of Toyama, \\ 3190 Gofuku, Toyama-shi, Toyama 930-8555, JAPAN
}

\begin{abstract}
This study focuses on the starting performance of small Darrieus wind turbines. Numerical simulations of the starting torque acting on a stationary wind turbine were performed to determine the wing section and wing setting angle that optimize the starting performance. Three different wing types, NACA0018, NACA4418 with its camber facing outward, and NACA4418 with its camber facing inward, were used for the analysis. The following conclusions were obtained. (1) With the wing setting angle of 0 degrees, symmetric arrangement of NACA0018 airfoils generated the highest minimum starting torque among the three types of wings tested. (2) With NACA0018, the starting performance can be further improved by setting the wings at a 5-degree outward angle because of an increase in the minimum starting torque.
\end{abstract}

Key words: Fluid Machinery, Darrieus Wind Turbine, Numerical Simulation, Starting Performance, Wing Section, Wing Setting Angle

\section{Introduction}

In recent years, increased concerns about environmental and safety issues have resulted in the promotion of the effective use of new energy sources, including solar energy, geothermal energy, small- to medium-scale hydraulic power generation, and wind power. NEDO (New Energy and Industrial Technology Development Organization) has been the leader in the research and development of new technologies for wind power generation under the New Sunshine Program for more than twenty years. As wind power generation uses the natural force of wind, power generation depends on the wind and terrain. In addition, it is necessary to consider the landscape and the noise caused by rotating wings of wind turbines. Therefore, it is difficult to build large-scale wind power generation plants in urban areas.

Wind turbines are generally classified into three types-propeller type, Darrieus type, and Savonius type. Because in Japanese urban districts wind direction changes throughout the year, vertical-axis-type wind turbines are more suitable compared to horizontal-axis-types such as propeller-type wind turbines, which must be positioned straight against the wind at all times. Among the vertical-axis-type turbines, Darrieus wind turbines are believed to have a greater potential because of their relatively high energy-conversion efficiency.
*Received 21 July, 2010 (No. T1-07-0509)
Japanese Original : Trans. Jpn. Soc. Mech.
Eng., Vol.74, No.739, B (2008),
pp.624-631 (Received 4 June, 2007)
[DOI: 10.1299/jee.6.302]

Copyright (c) 2011 by JSME 
In the past, Darrieus wind turbines have been studied by various researchers. In particular, there have been comprehensive studies on Darrieus cross-current water turbines on issues such as the effect of the geometrical attitude of wings, estimation methods for wing performance, and effective use of low-head water power ${ }^{(1)-(3)}$. On the other hand, studies on Darrieus wind turbines include the measurement of fluctuation torque acting on wings $\mathrm{s}^{(4)}$ and stall characteristics using visual simulation ${ }^{(5)(6)}$. In addition, details of the wind stream around a Darrieus wind turbine have been studied by numerical simulations ${ }^{(7)}$.

This study focuses on the starting performance of small Darrieus wind turbines ${ }^{(8)(9)}$, which are designed for installation at ordinary households. When considering the performance of a wind turbine, both the energy production performance and the starting performance are important. However, it is unlikely that a thorough research on the wind characteristics is carried out before the installation of a small wind turbine. Unlike large-scale wind turbines, which are installed solely for the generation of power, installation sites for small wind turbines do not necessarily satisfy the various requirements for efficient wind power generation. Therefore, it is reasonable to consider that the starting performance would relatively be more important because a wind turbine with better starting performance could operate in mild winds. Therefore, this study aims to determine, using numerical simulation, the starting performance of a small Darrieus wind turbine used for the analysis of wind and energy production performance in a previous study ${ }^{(10)}$.

First, starting torque of a miniature wind turbine was determined using a wind tunnel test and compared with that obtained through a numerical simulation to verify the accuracy of the numerical simulation. Then a numerical simulation was performed to determine the influence of the wing section and wing setting angle on a small Darrieus wind turbine.

\section{Nomenclature}

$\begin{array}{llll}c & : & \text { Wing chord length } & {[\mathrm{m}]} \\ C_{p} & : & \text { Pressure coefficient }\left(\left(P-P_{r e f}\right) / 0.5 \rho U^{2}\right) & {[-]} \\ C_{t} & : & \text { Torque coefficient }\left(T / 0.5 \rho U^{2} h D R\right) & {[-]} \\ d t & : & \text { Time step } & {[\mathrm{s}]} \\ D & : & \text { Wind turbine diameter } & {[\mathrm{m}]} \\ h & : & \text { Wing span length } & {[\mathrm{m}]} \\ N & : & \text { Number of wings } & {[-]} \\ P & : & \text { Pressure } & {[\mathrm{Pa}]} \\ P_{r e f} & : & \text { Reference pressure (inlet boundary pressure }) & {[\mathrm{Pa}]} \\ R & : & \text { Turbine radius } & {[\mathrm{m}]} \\ R e & : & \text { Reynolds number around a turbine }(U D / v) & {[-]} \\ R e_{w} & : & \text { Reynolds number around a wing }(U c / v) & {[-]} \\ T & : & \text { Torque } & {[\mathrm{Nm}]} \\ U & : & \text { Free-stream speed } & {[\mathrm{m} / \mathrm{s}]} \\ \beta & : & \text { Wing setting angle } & {[\mathrm{deg}]} \\ \gamma & : & \text { Angle of free-stream velocity } & {[\mathrm{deg}]} \\ \mu & : & \text { Viscosity } & {[\mathrm{Pa} \mathrm{s}]} \\ v & : & \text { Kinematic viscosity } & {[\mathrm{m} / \mathrm{s}]} \\ \rho & : & \text { Density } & {\left[\mathrm{kg} / \mathrm{m}^{3}\right]} \\ \sigma & : & \text { Solidity }(N c / R) & {[-]}\end{array}$

\section{Experimental Apparatus and Calculation Model}

In order to verify the accuracy of the numerical simulation, a wind tunnel test was performed. A Göttingen-type (circulating) wind tunnel was used to measure the starting 
torque acting on a miniature wind turbine.

\subsection{Miniature Model}

Figure 1 shows the miniature model of the Darrieus wind turbine used in this study. The specifications of the model are listed in Table 1. The diameter (D) was $200 \mathrm{~mm}$ and the height $(h)$ was $200 \mathrm{~mm}$. A NACA0018 airfoil of $30 \mathrm{~mm}$ chord length was used for the wing section with an aspect ratio of 6.7. The miniature model had four wings, each having a solidity $(\sigma)$ of 1.2 . The four wings were attached to a wing-edge plate at a quarter of the chord length from the front edge of the wing. The wing-edge plate was made from aluminum and has a $220 \mathrm{~mm}$ diameter and $2 \mathrm{~mm}$ thickness. An S45C rod of $10 \mathrm{~mm}$ diameter was used as the rotating shaft and was supported by bearings to ensure smooth rotation. In the test, the free-stream speed from the wind tunnel was set at $U=16 \mathrm{~m} / \mathrm{s}$, so that the Reynolds number of the stream around the small wind turbine (diameter $1.67 \mathrm{~m}$, speed $2 \mathrm{~m} / \mathrm{s}$ ) used in this study would be close to that of the model. The Reynolds number $(\mathrm{Re})$ of the stream around the wind turbine was taken to be $R e=2.04 \times 10^{5}$.
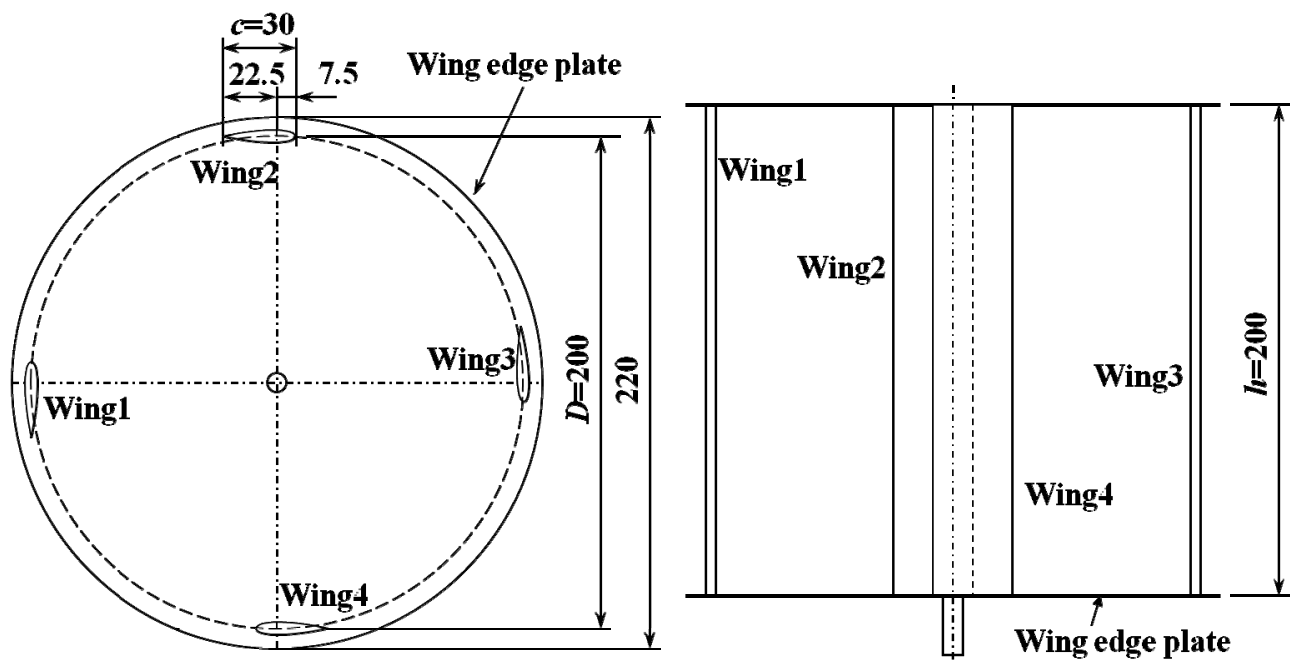

Fig. 1 Miniature model of the Darrieus wind turbine

Table 1 Specifications of the wind turbine model

\begin{tabular}{|l|l|}
\hline Wing chord length $c$ & $30 \mathrm{~mm}$ \\
\hline Wind turbine diameter $D$ & $200 \mathrm{~mm}$ \\
\hline Wing span $h$ & $200 \mathrm{~mm}$ \\
\hline Number of wings $N$ & 4 \\
\hline Solidity $\sigma$ & 1.2 \\
\hline Wing section & NACA0018 \\
\hline
\end{tabular}

\subsection{Experimental Apparatus}

Figure 2 shows the outline of the experimental apparatus. A Göttingen-type (circulating) wind tunnel was employed in the test. The outlet and intake openings of the wind tunnel were circular with diameters of $400 \mathrm{~mm}$ and $600 \mathrm{~mm}$, respectively. The air was sucked in from the intake by an axial fan and discharged through a nozzle into the test section after passing through the internal passage. During the test, the wind speed of the discharged air was monitored and the axial fan speed was adjusted so that the required wind speed $(U=16$ $\mathrm{m} / \mathrm{s}$ ) was obtained.

For the torque measurement, a torque detector and a torque indicator were used. The 
driving shaft of the torque detector was coupled with the miniature wind turbine shaft using a flexible coupling, and a $150 \mathrm{~mm}$ diameter aluminum plate, which functions as a disc brake, was attached to the load side of the torque detector. This brake was used to hold the wind turbine at an arbitrary angle, and the starting torque was measured at various angles of the wind $(\gamma)$ from 0 to 75 degrees at 15-degree intervals. The analog output of the torque indicator was captured by a PC using an AD converter (sampling cycle: $0.1 \mathrm{~s}$ ). The measurement was performed for $30 \mathrm{~s}$ and the average of the torque recorded was used as the starting torque. The measurement was repeated four times under identical conditions, and the average and standard deviation were determined.
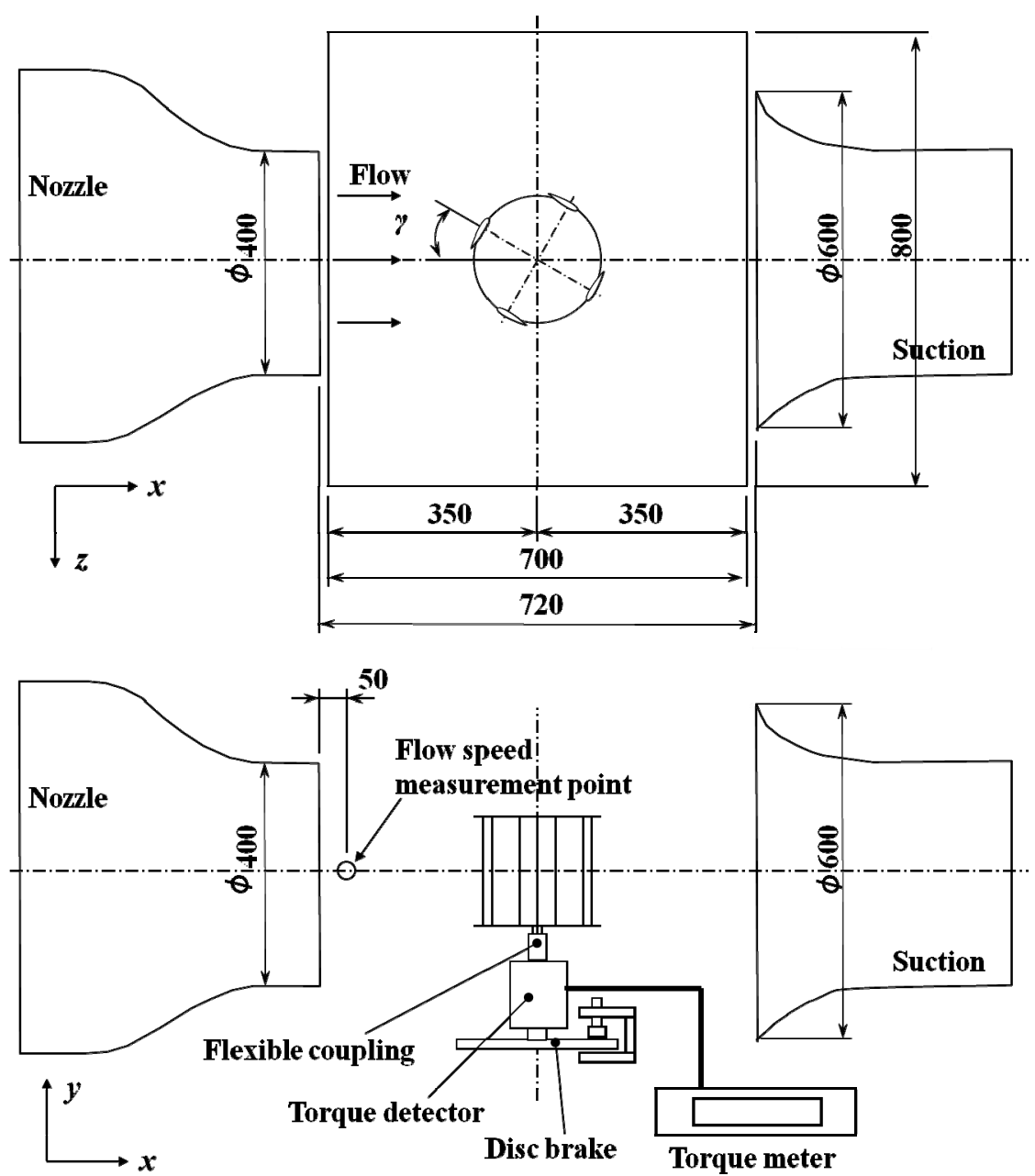

Fig. 2 Outline of the experimental apparatus

\subsection{Numerical Simulation Model}

Figure 3 gives general information on the numerical simulation model. For the analysis, a general-purpose CFD software CFD2000 (developed by Adaptive Research) was used. A two-dimensional model was used because the wing with an aspect ratio of 6.7 or higher is expected to show a two-dimensional nature to some extent, together with the fact that it is convenient to study several parameters using a two-dimensional model. The analysis area was set as a circular area of a diameter 15 times greater than that of the wind turbine, as shown in Fig. 3(a). The left hand side of the analysis area was set as the inlet boundary condition with a steady-stream speed $U$. The right hand side is considered as the outlet boundary condition and the pressure was fixed at $0 \mathrm{~Pa}$. The inlet air was assumed to have the following physical properties: viscosity $(\mu)=1.85 \times 10^{-5} \mathrm{~Pa}$ s and density $(\rho)=1.177$ 
$\mathrm{kg} / \mathrm{m}^{3}$. In addition, the symbols $\gamma$ and $\beta$ denote the direction of the steady stream and wing setting angle, respectively, as shown in Fig. 3(b). Three different wing types, NACA0018, NACA4418 with its camber facing outward, and NACA4418 with its camber facing inward, were used for the analysis. Figure 3(c) shows the different configurations for NACA4418.

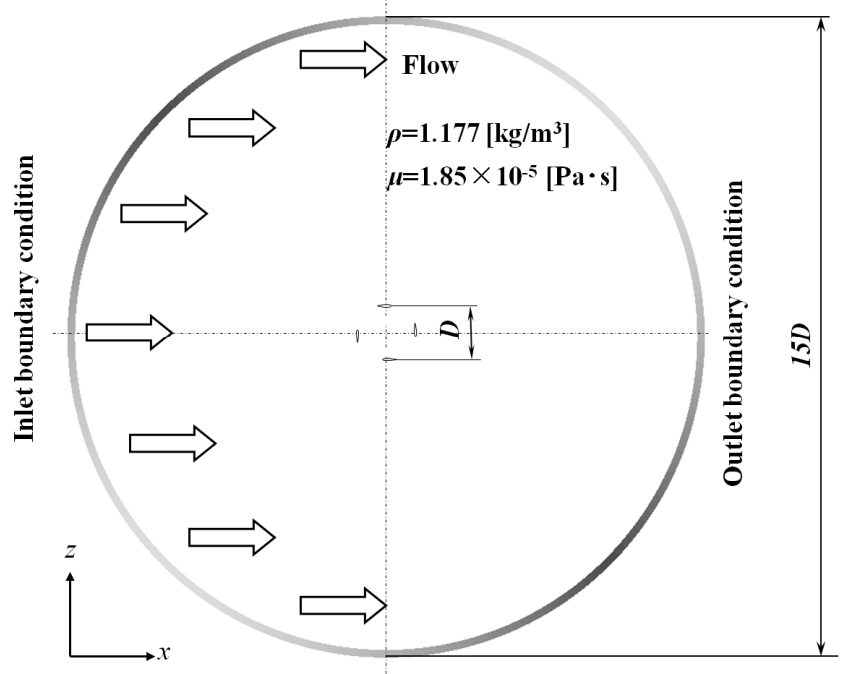

(a) Computational conditions

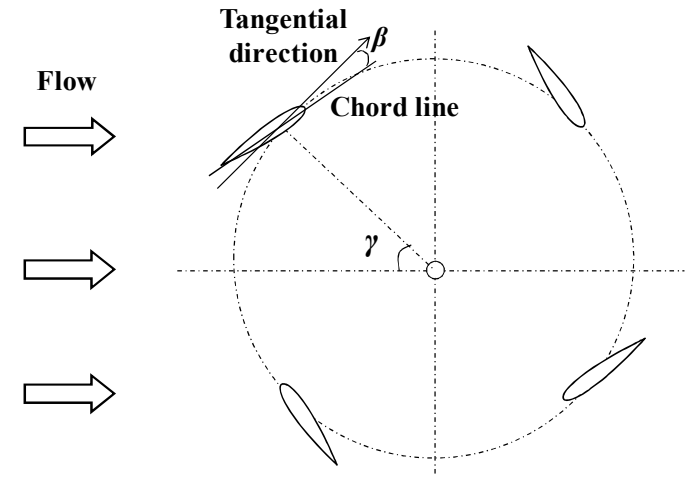

(b) Direction of the steady stream $\gamma$ and wing setting angle $\beta$

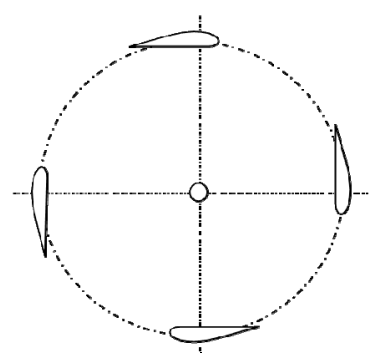

Camber outward

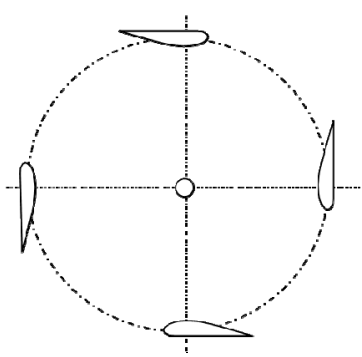

Camber inward

(c) Configurations for NACA4418

Fig. 3 Schematic diagrams of the numerical simulation model

Discretization based on the finite volume method was performed, with the equation of continuity and the Navier-Stokes equation as the governing equations of flow. For the convective term, the second-order TVD upwind scheme was applied because of its computational stability ${ }^{(11)}$. The time integration was done by the first-order Euler explicit method. For the definitions of physical values, such as velocity and pressure, the collocated 
arrangement was used, and in order to avoid the checkerboard phenomenon of the pressure field, the Rhie-Chow method was applied. For the coupling of velocity and pressure, the pressure implicit with splitting of operations (PISO) method was used. The time interval was calculated for each step by setting the CFL value as 0.8 and obtaining a value that does not exceed this CFL value. On the average, the interval $d t$ was approximately $2 \times 10^{-5} \mathrm{~s}$.

Figure 4 shows the computational mesh of the entire analysis domain and grid distribution around the wings. The computational mesh was built using Type $\mathrm{H}$ single-block structured grids, and the wings and rotational shaft were treated by masking. In order to capture the vortices and separations generated around the wings, grids were concentrated around the wings. Assuming a Reynolds number $\left(\operatorname{Re}_{\mathrm{w}}\right)$ with the given chord length $(c)$ and velocity of free-stream $(U)$, the thickness of the laminar boundary layer $(\delta)$ was estimated as $\mathrm{c} / \sqrt{R e_{w}}$, and the grid was formed such that about five computation mesh points would be located within the boundary layer. The minimum thickness of the grids on the wing surface was determined using the value of $0.1 \mathrm{c} / \sqrt{R e_{w}}$ as a reference after performing several computational trials. There were a total of 138,384 grids -372 in the direction of the $\mathrm{x}$-axis and 372 in the direction of the y-axis. The computation was performed for a period of $8 \mathrm{~s}$, and the still start torque was obtained as the average value for $7 \mathrm{~s}-$ from $1 \mathrm{~s}$ to $8 \mathrm{~s}$. For this computation, a CPU time of approximately 35 hours was necessary per case.

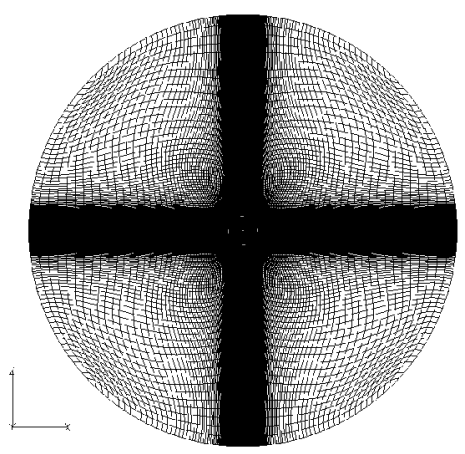

(a) Computational mesh

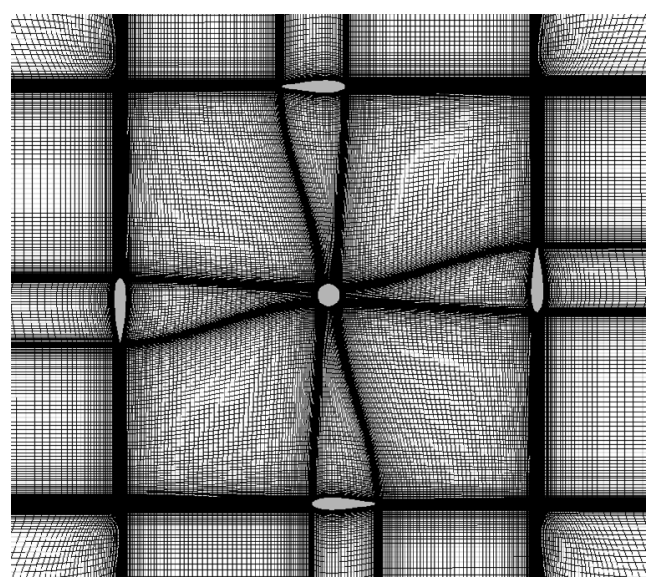

(b) Grid distribution around the wings

Fig. 4 Computational mesh around the Darrieus wind turbine

\section{Results and Discussion}

\subsection{Verification of the Accuracy of Numerical Simulation}

The accuracy of numerical simulation was verified by comparing the starting torque obtained by the wind tunnel test using a miniature wind turbine and that by numerical simulation. The comparison was made for the wing type NACA0018 and the wind speed $U$ $=16 \mathrm{~m} / \mathrm{s}$.

Figure 5 shows the results of the comparison. The horizontal axis represents the wind direction and the vertical axis represents the starting torque. It is evident that the experimental results and computed values match qualitatively. The aspect ratio of the wings used in the experiment is rather large at 6.7. In addition, since the round plate on which the four wings were attached can also be expected to play the role of a wing-edge plate, effects of the wing-edge vortices are considered to be small. Even so, the computed values 
overestimate the starting torque by 30 percent when compared with the test results. The reason for this is assumed to be the use of two-dimensional analysis, in which the three-dimensional property of the wake was neglected. Izumi et al. report that, in an analysis of the flow fields around an infinitely long cylinder (two-dimensional cylinder), a two-dimensional numerical simulation would overestimate the drag by about 30 percent compared to a three-dimensional numerical simulation and actual experimental test results-also a consequence of neglecting the three-dimensional property of the wake ${ }^{(12)}$. In addition, because the numerical simulation performed in this study does not take into account turbulence, dissipation of separation vortices from the front and rear edges of the wings is underestimated, resulting in a stronger negative pressure on the wing surface. This is considered to be another factor causing the discrepancy. Since the computed values reproduce the experimental results qualitatively, the two-dimensional simulation is considered useful in a comparative assessment of parameter studies.

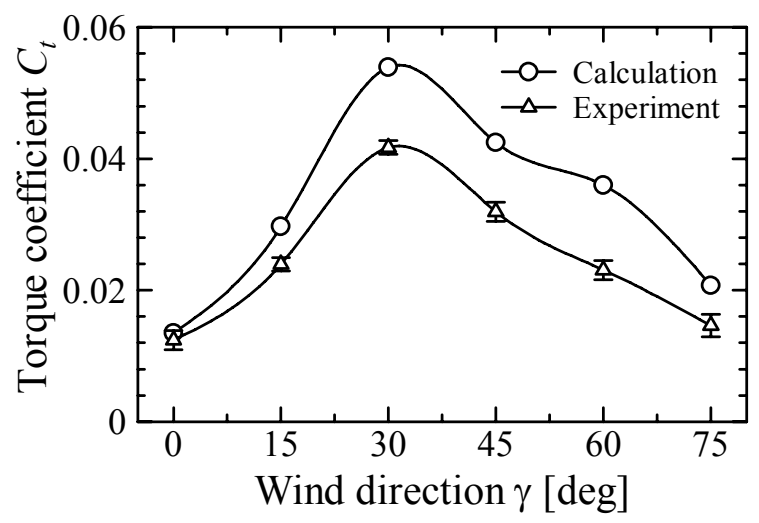

Fig. 5 Comparison of the starting torque (NACA0018)

\subsection{Influence of Differences in Wing Sections}

This section and the next few sections focus on a small Darrieus wind turbine. The wind turbine had four straight wings, and a rotor diameter $(D)$ of $1.67 \mathrm{~m}$, height $(h)$ of $2 \mathrm{~m}$, and chord length $(c)$ of $265 \mathrm{~mm}$. The starting torque was determined assuming the wind turbine self-starts at the wind speed of $2 \mathrm{~m} / \mathrm{s}$ (Reynolds number $=2.12 \times 10^{5}$ ). Figure 6 shows changes in the starting torque against the wind direction for different wings. Wings used were NACA0018, NACA4418 with its camber facing outward, and NACA4418 with its camber facing inward. It is evident that the starting torque is lowest at the wind direction of 0 degrees and highest at the wind direction of 30 degrees for all wings. A higher minimum starting torque and a sufficient starting torque independent of wind direction are important factors in the starting performance of a wind turbine. Therefore, NACA0018 is considered to have the best starting performance as it generates a higher starting torque compared to other wings at the wind direction of 0 degrees, where the starting torque is the lowest. When two different configurations of NACA4418, with its camber facing outward and inward, are compared, higher torque is obtained for the inward camber arrangement for the wind direction of 15 to 45 degrees. However, for the wind directions of 45 to 75 degrees and 0 degrees, the outward camber arrangement produces higher torque. 


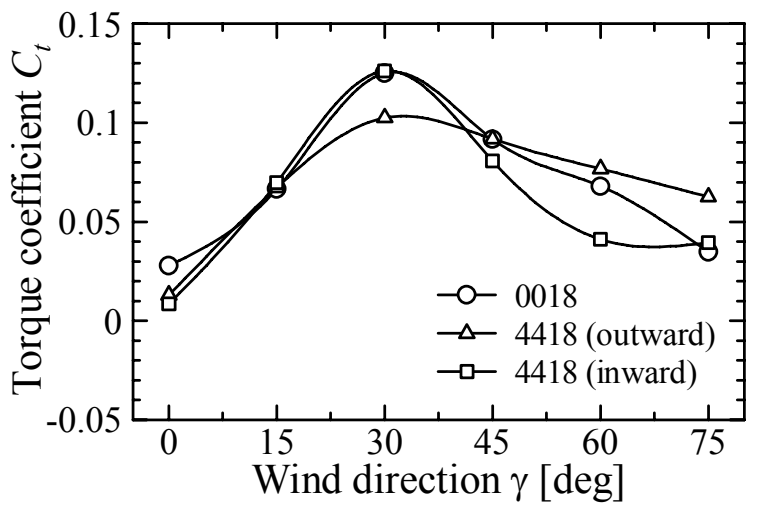

Fig. 6 Changes in the starting torque against the wind direction for different wings

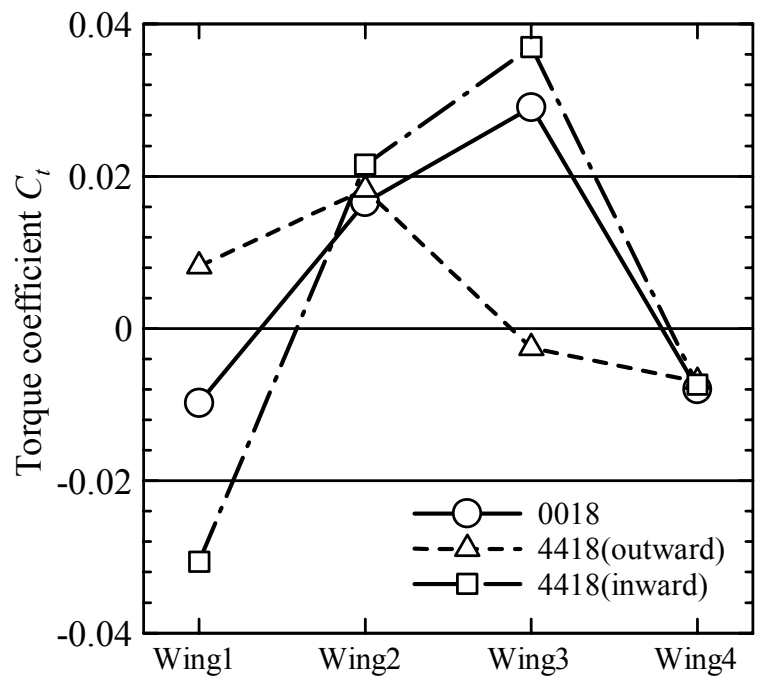

Fig. 7 Comparison of the starting torque on wings 1 to 4 for the wind direction of 0 degrees

Figure 7 shows a comparison of the starting torque on wings 1 to 4 for the wind direction of 0 degrees. Figure 8 shows the comparison of average pressure fields around three different wings. The average of pressure fields was obtained by averaging the pressure fields obtained from $1 \mathrm{~s}$ to $8 \mathrm{~s}$ with an interval of $0.02 \mathrm{~s}$. According to Fig. 7, NACA0018 and NACA4418 with its camber inward exhibit similar tendencies, in which the starting torque is generated from the drag on wing 2 and lift on wing 3 . The drag on wing 4 does not contribute to the starting torque for all wing types. 


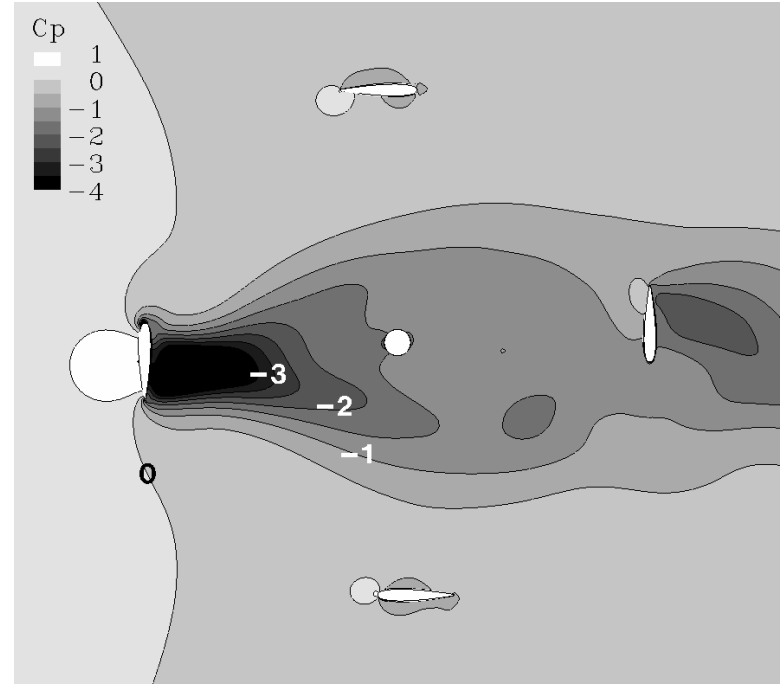

(a) NACA0018 wings

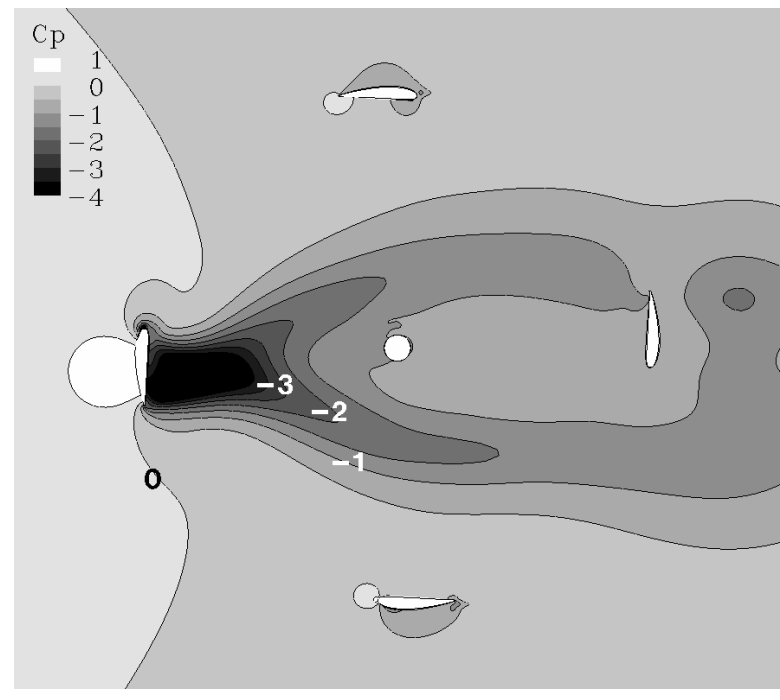

(b) NACA4418 wings with its camber facing outward

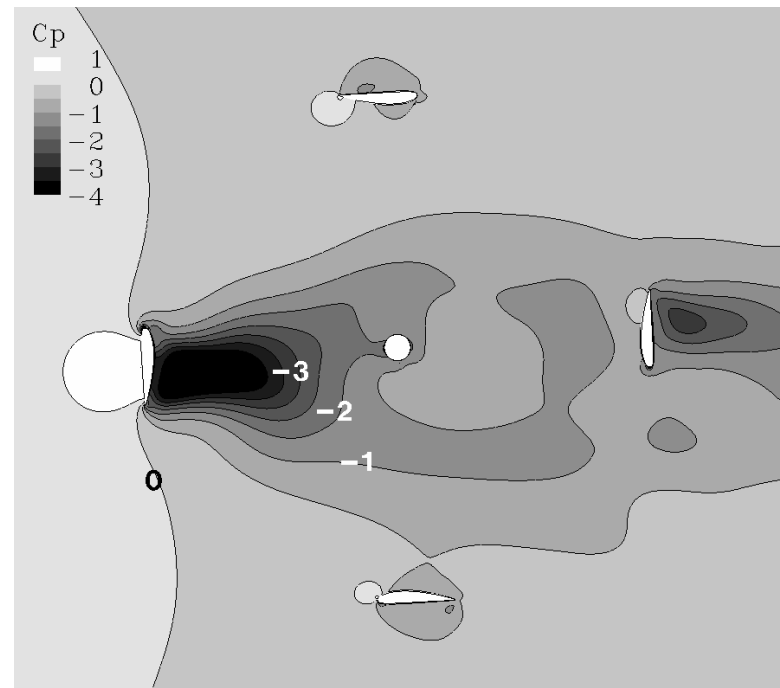

(c) NACA4418 wings with its camber facing inward

Fig. 8 Comparison of the pressure fields around three different wings (Wind direction: 0 degrees) 
As exhibited in Fig. 8, wing 1 generates huge differences in the pressure. However, by looking at Fig. 7, wing 1 does not contribute to the starting torque except in the outward camber arrangement of NACA4418. Figure 9 shows the pressure distribution on the surface of wing 1 with the $\mathrm{x}$-axis representing the distance from the rear edge in counterclockwise movement. The $\mathrm{x}$-axis shows non-dimensional values relative to the wind turbine diameter. Figure 9 shows that the differences in the pressure distribution between wing types are not significant. The torque distribution on different grid points around wing 1 is shown in Fig. 10. The grid points are numbered in a counterclockwise order, starting from the rear edge. There are 84 grids around the wing, wherein the grid number at the rear edge is 1 and that at the front edge is 43 . By adding up the torque values at each grid point, the starting torque that affects wing 1 can be obtained. Figure 10 shows that the torque distribution is different for each type of wing. In the case of NACA4418 with its inward camber, the negative pressure at the rear edge of the wing generates the highest braking torque, together with the fact that the starting torque obtained from the front edge is low; this is why no starting torque is generated as a whole. On the other hand, in the case of NACA4418 with its outward camber, although the starting torque generated at the front edge is not higher than that of NACA0018, the braking torque generated by the negative pressure at the rear edge is lower; this is why this wing generates the highest starting torque among the three wings as far as wing 1 is concerned.

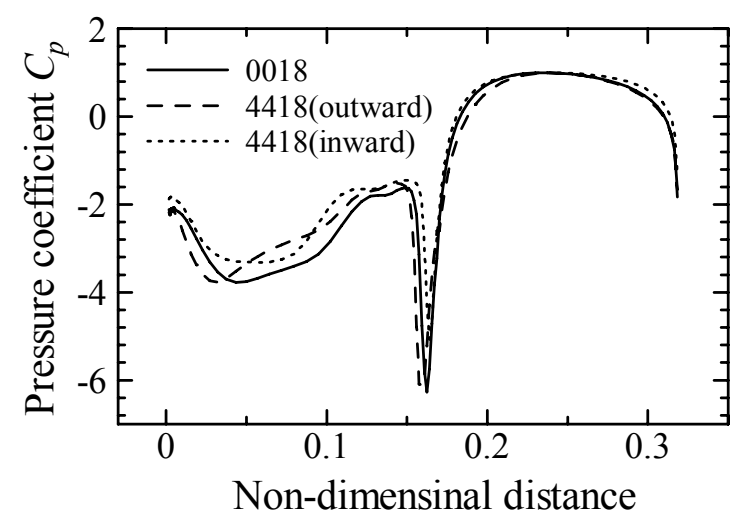

Fig. 9 Pressure distribution on the surface of wing 1

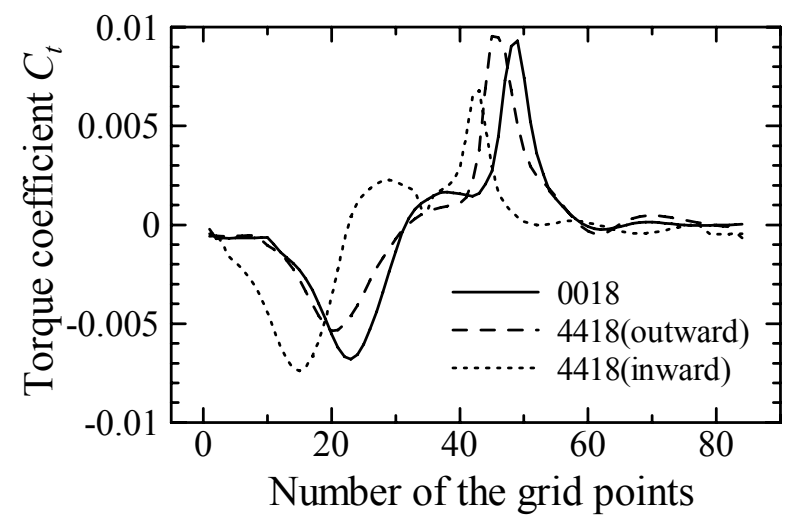

Fig. 10 Torque distribution on different grid points around wing 1 


\subsection{Influence of Wing Setting Angle}

Among the wing sections discussed in Section 4-2, NACA0018 was selected for its best starting performance and was studied for changes in the starting torque with different wing setting angles. Figure 11 shows a plot of the starting torque versus the wind direction for various wing setting angles. Wing setting angles of 3 and 5 degrees both inward and outward and 8 degrees outward were examined. The negative sign $(-)$ denotes an outward wing setting angle. Looking at the wind direction of 0 degrees, where the starting torque is the lowest, the obtained torque is larger by about 43 percent for a wing setting angle of 5 degrees inward and by about 34 percent for a wing setting angle of 5 degrees outward compared to the case where the wing setting angle is 0 degrees. However, for a wing setting angle of 5 degrees inward, the starting torque is significantly lower at a wind direction of 30 degrees to 75 degrees, and therefore, the starting performance is not considered to have improved. On the other hand, the wing setting angle of 5 degrees outward produces a relatively high and stable torque regardless of wind direction; thus, the starting performance improves with this setting angle.

Figure 12 shows a comparison of the starting torque on wings 1 to 4 for the wind direction of 0 degrees. The graphs indicate that, by setting the wings at a 5-degree outward angle, the starting torque generated by wing 1 increases. In the meantime, starting torque generated by the drag on wing 2 and lift on wing 3 becomes smaller and, in particular, the torque on wing 3 is very close to 0 . The drag on wing 4 does not contribute to the starting torque in either case.

Figure 13 shows the average pressure field with the wing setting angle of 5 degrees outward for NACA0018. This distribution is compared with the pressure field of NACA0018 with a wing setting angle of 0 degrees, which is shown in Fig. 8(a). As indicated by Fig. 13, wing 1 causes big differences in pressure in its surrounding area. Figure 14 shows the pressure distribution on the wing surface, similar to Fig. 9. The horizontal axis shows non-dimensional values relative to the wind turbine diameter. According to Fig. 14, the pressure distribution around the wing does not change much by changing the wing setting angle. Figure 15 shows the torque distribution on grids around the wing section, similar to Fig. 10. This torque distribution indicates that, although the starting torque at the front edge remains approximately the same, the braking torque due to the negative pressure at the rear edge decreases by setting the wings at a 5-degree outward angle and this effectively increases the starting torque. As a result, it is possible to obtain a greater starting torque by changing the wing setting angle outwards by 5 degrees.

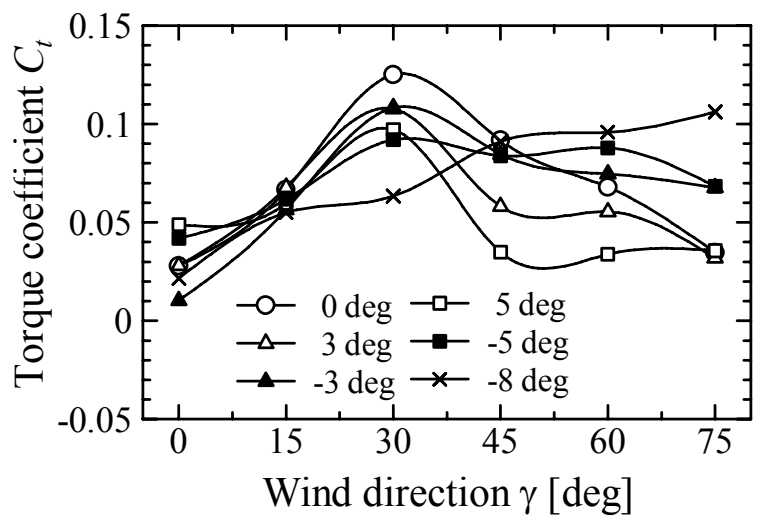

Fig. 11 Starting torque versus the wind direction for various wing setting angles 


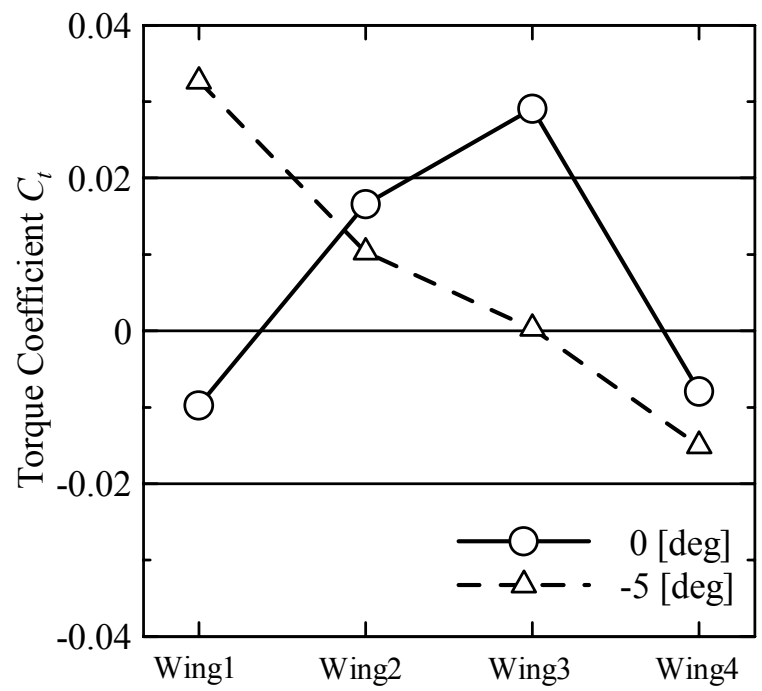

Fig. 12 Comparison of the starting torque on wings 1 to 4 for the wind direction of 0 degrees

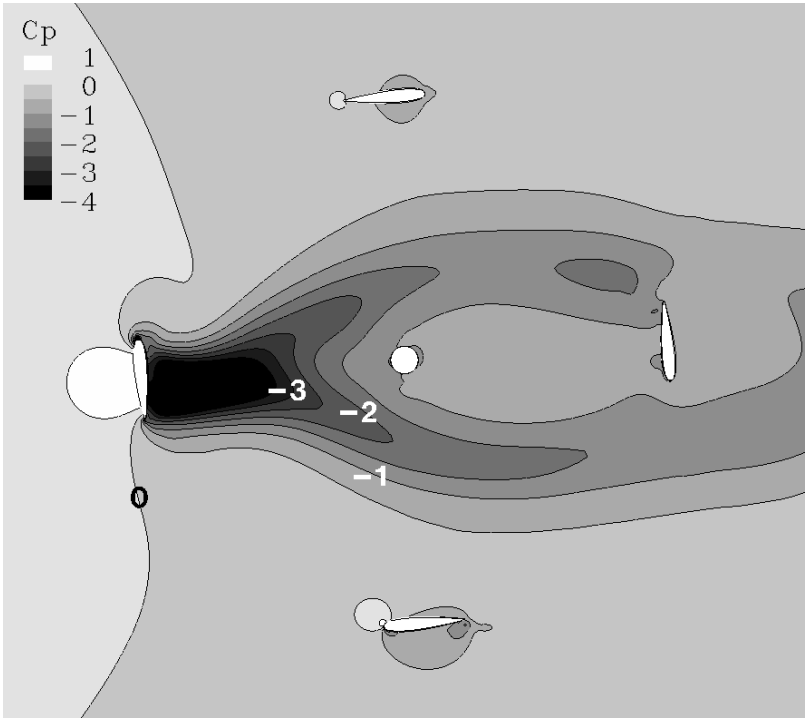

Fig. 13 Average pressure field with the wing setting angle of 5 degrees outward for NACA0018 (Wind direction: 0 degrees)

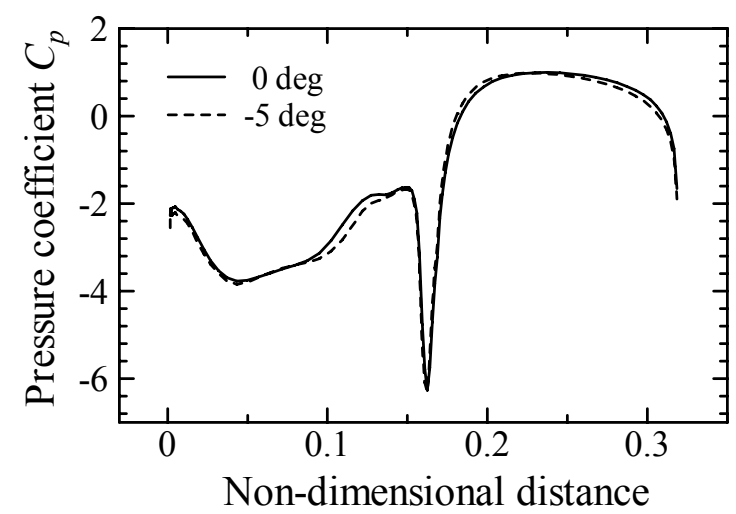

Fig. 14 Pressure distribution on the surface of wing 1 


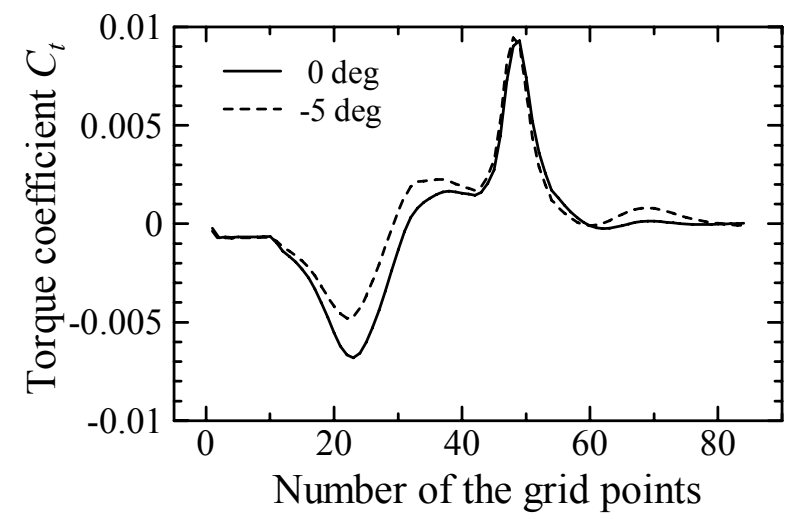

Fig. 15 Torque distribution on different grid points around wing 1

\section{Conclusions}

In an attempt to improve the performance of Darrieus wind turbines with straight wings, numerical simulations of the starting torque acting on a stationary wind turbine were performed to determine the wing section and wing setting angle that optimize the starting performance. The following conclusions were obtained.

(1) With the wing setting angle of 0 degrees, symmetric arrangement of NACA0018 airfoils generated the highest minimum starting torque among the three types of wings tested.

(2) With NACA0018, the starting performance can be further improved by setting the wings at a 5 -degree outward angle because of an increase in the minimum starting torque.

\section{References}

(1) Takamatsu, Y., Furukawa, A., Okuma, K., Takenouchi, K., Effects of Geometrical Attitude of Blade on Hydrodynamic Performance of Darrieus -Type Cross-Flow Water Turbine, Transactions of the Japan Society of Mechanical Engineers, Series B, Vol. 50, No. 458(1984), pp. 2631-2634.

(2) Takamatsu, Y., Furukawa, A., Takenouchi, K., Okuma, K., Experimental Consideration in an Approximate Method for Estimating the Blade Perfomance of Darrieus-Type Cross-Flow Water Turbine, Transactions of the Japan Society of Mechanical Engineers, Series B, Vol. 57, No. 541(1991), pp. 3110-3116.

(3) Furukawa, A., Okuma, K., Gajanayake, P. A., Tagaki, A., Basic Study of Low Head Water Power Utilization by Using Darrieus-Type Turbine, Transactions of the Japan Society of Mechanical Engineers, Series B, Vol. 64, No. 624(1998), pp. 2534-2540.

(4) Okubayashi, T., Kage, K., Ishimatsu, K., Study of Darrieus Wind Turbine (Fluctuation Torque acting on a Single Blade), Proceedings of the Kyushu Branch Meeting of the Japan Society of Mechanical Engineers, No.018-2(2001), pp. 127-128.

(5) Fujisawa, N., Hori, Y., Investigation of Flow Field around a Darrieus Rotor by Flow Visualization and Image Analysis, Transactions of the Japan Society of Mechanical Engineers, Series B, Vol. 63, No. 606(1997), pp. 590-595.

(6) Fujisawa, N., Shibuya, S., Takuno, T., Visualization and Image Analysis of Dynamic Stall Phenomenon for a Darrieus Wind Turbine, Transactions of the Japan Society of Mechanical Engineers, Series B, Vol. 65, No. 638(1999), pp. 3374-3379.

(7) Ishimatsu, K., Kage, K., Okubayashi, T., Numerical Simulation for Flow Fields of Darrieus Turbine, Transactions of the Japan Society of Mechanical Engineers, Series B, Vol. 61, No. 587(1995), pp. 2543-2548. 
(8) Nahasa, M.N., A self-starting darrieus-type windmill, Energy, Vol. 18, No. 9(1993), pp. 899-906.

(9) Takahiro KIWATA, Tatsuro YAMADA, Tetsuyoshi KITA, Shinei TAKATA, Nobuyoshi KOMATSU and Shigeo KIMURA, Performance of a Vertical Axis Wind Turbine with Variable-Pitch Straight Blades utilizing a Linkage Mechanism, Journal of Environment and Engineering, Vol. 5, No. 1 (2010), pp.213-225 .

(10) Tanaka, F., Kawaguchi, K., Tomioka, M., Study on Wind Measurements and Annual Energy Production of a Darrieus Wind Turbine, Transactions of the Japan Society of Mechanical Engineers, Series B, Vol. 73, No. 735(2007), pp. 2283-2289.

(11) Yee, H. C., A Class of High-Resolution Explicit and Implicit Shock-Capturing Methods, NASA TM101088, (1989).

(12) Izumi, H., Taniguchi, N., Kawata, Y., Kobayashi, T., Adachi, T., Three-Dimensional Flow Analysis around a Circular Cylinder (1st Report, In the Case of a Stationary Circular Cylinder), Transactions of the Japan Society of Mechanical Engineers, Series B, Vol. 60, No. 579(1994), pp. 3797-3804. 